Research Article

\title{
A comparative study of the effect of dexmedetomidine and lignocaine on hemodynamic responses and recovery following tracheal extubation in patients undergoing intracranial surgery
}

\author{
Nita D. Gosai*, Amita H. Jansari, Rekha N. Solanki, Dipika P. Patel, Dhvanan N. Prajapati, \\ Bipin M. Patel
}

Department of Anaesthesia, Gujarat Cancer \& Research Institute, Civil Hospital, Asarwa, Ahmedabad, Gujarat, India

Received: 27 February 2015 Accepted: 07 March 2015

*Correspondence to:

Dr. Nita D. Gosai,

Email: dr.nitagosai@gmail. com

Copyright: (C) the author(s), publisher and licensee Medip Academy. This is an openaccess article distributed under the terms of the Creative Commons Attribution NonCommercial License, which permits unrestricted noncommercial use, distribution, and reproduction in any medium, provided the original work is properly cited.

\begin{abstract}
Background: Recovery from general anesthesia and extubation is a period of intense physiological stress for patients. The most feared complications after intracranial surgery are development of an intracranial hematoma and major cerebral edema. Both may result in cerebral hypoperfusion and brain injury. Thus, the anesthetic emergence of a neurosurgical patient should include maintenance of stable respiratory and cardiovascular parameters. Minimal reaction to the endotracheal tube removal prevents sympathetic stimulation and increases in venous pressure. In our study, we compared dexmedetomidine $\mathrm{HCl}$, lignocaine $\mathrm{HCl}$ and placebo to blunt stress response and providing a smooth transition from extubation phase.

Methods: 75 ASA Grade I and II patients aged 18-60 years scheduled for elective intracranial surgery for intracranial space occupying lesions were randomly divided into three groups of 25 each. Balanced general anesthesia was given. Inhalation anesthetic was discontinued and after return of spontaneous respiration patient in Group D received injection dexmedetomidine $0.5 \mu \mathrm{g} / \mathrm{kg}$ intravenous (IV), Group X received injection lignocaine $1.5 \mathrm{mg} / \mathrm{kg}$ IV and Group P received $10 \mathrm{ml}$ normal saline IV over $60 \mathrm{sec}$. Heart rate (HR), mean arterial pressure (MAP), quality of extubation were measured at 1, 3, 5, 10, 15 mins interval after extubation. Emergence time and extubation time were noted and quality of extubation was evaluated on cough grading. Results: There was a significant decrease in MAPs and HR in Group D as compared to Group L and Group P $(\mathrm{p}<0.05)$ at all-time interval after extubation. Extubation quality score of the majority of patients was 1 in Group D, 2 in Group X, and 3 in Group P $(\mathrm{p}<0.001)$. The duration of emergence and extubation were comparable in all three groups. Sedation score of the most patient was $3(44 \%)$ in Group D and 2 $(56 \%)$ in Group X. Six patients in Group D and 1 patient in Group X had bradycardia. Conclusion: Single bolus dose of IV dexmedetomidine $\mathrm{HCl} 0.5 \mathrm{mg} / \mathrm{kg}$ given before tracheal extubation effectively attenuates hemodynamic response to extubation as compared to $1.5 \mathrm{mg} / \mathrm{kg}$ lignocaine $\mathrm{HCl}$.
\end{abstract}

Keywords: Dexmedetomidine, Lignocaine, Tracheal extubation, Intracranial surgery

\section{INTRODUCTION}

Early recovery and extubation in the operating room is the preferred method when the pre-operative state of consciousness is relatively normal and surgery does not involve critical brain areas or extensive manipulation. In the complicated or unstable patient, the risks of early extubation may outweigh the benefits. ${ }^{1}$ Patients with increased intracranial pressure (ICP) are prone to severe cardiac and or cerebral complications following emergence from general anesthesia and during the recovery period.
A variety of drugs such as esmolol, alfentanil, diltiazem, verapamil, fentanyl, and lidocaine have been used to control hemodynamic changes and upper airway tract events. ${ }^{2}$ Our aim is to maintain hemodynamic stability during extubation and recovery period.

Anesthesiologists play a key role in the prevention of postoperative neurosurgical complications because many factors that influence cerebral blood flow, cerebral metabolism, and ICP are under their control. Dexmedetomidine is a potent and highly selective $\alpha-2$ adrenoceptor agonist with 
sympatholytic, sedative, amnestic, analgesic, and anesthetic sparing properties, without respiratory depression, making it a useful and safe drug during emergence from anesthesia. There is increasing evidence of its organ protective effects against ischemic and hypoxic injury, including cardioprotection, neuroprotection, and renoprotection. ${ }^{2}$

\section{METHODS}

The study was approved by hospital ethics committee to do randomized prospective study in 75 patients of ASA I and II, aged 18-60 years undergoing intracranial surgery for intracranial space occupying lesions. Patients with ischemia, congestive cardiac disease, renal, hepatic, and respiratory dysfunction, patients taking beta blocker, digoxin, patients with heart rate $(\mathrm{HR})<60 \mathrm{bpm}$, and blood pressure $<100 / 60$, history of allergic reactions to study drugs, history of sleep apnea, mallampatti Grade 3 and 4 were excluded from study.

After taking informed consent, patients were randomly divided into three groups of 25 each. All these patients were evaluated pre-operatively for fitness of anesthesia and kept fasting for 6-8 hrs. All patients received tablet phenytoin sodium and tablet dexamethasone in the morning of surgery. In the operation theater after applying monitor in the form of five lead electrocardiogram, HR, pulse oximetry and non-invasive blood pressure, intravenous (IV) line was secured with wide bore cannula. General anesthesia was induced with glycopyrrolate $0.2 \mathrm{mg}$, fentanyl $4 \mu \mathrm{g} / \mathrm{kg}$, followed by thiopentone sodium $4-5 \mathrm{mg} / \mathrm{kg}$ IV. Tracheal intubation was facilitated with vecuronium $0.1 \mathrm{mg} / \mathrm{kg} \mathrm{IV}$. All the patients were mechanically ventilated at a fresh gas flow of $2 \mathrm{~L} / \mathrm{mins}$ to maintain an end-tidal carbon dioxide $\left(\mathrm{EtCO}_{2}\right)$ of $30 \mathrm{mmHg}$. Anesthesia was maintained with sevoflurane 0.8-1.0 minimum alveolar concentration (MAC) with nitrous oxide and oxygen (60:40) MAC and vecuronium infusion.

No additional opioid was given after induction. The values for HR, systolic arterial pressure (SAP), diastolic arterial pressure (DAP), and mean arterial pressure (MAP) obtained just before administration of the study drug were used as baseline.

A computer-generated randomization chart was used to assign each patient to either the dexmedetomidine group (Group D, n=25), lignocaine group (Group L, $n=25$ ) or placebo group (Group P, $n=25$ ). At the end of the surgery as the inhalation anesthetic and nitrous oxide was discontinued and after returning of spontaneous efforts, patients in Group D received $0.5 \mu \mathrm{g} / \mathrm{kg}$ dexmedetomidine (diluted with $10 \mathrm{ml}$ normal saline), Group $\mathrm{L}$ patients received lignocaine $1.5 \mathrm{mg} / \mathrm{kg}$ (diluted with $10 \mathrm{ml}$ normal saline) and Group P patients' received $10 \mathrm{ml}$ of normal saline.

Over $60 \mathrm{sec}$ and neuromuscular block was reversed with neostigmine $0.05 \mathrm{mg} / \mathrm{kg}$ and glycopyrrolate $0.01 \mathrm{mg} / \mathrm{kg}$. The trachea was extubated when patient followed commands. HR and MAP were noted during tracheal extubation. Hemodynamic variables were noted before administering study drug and then immediately after extubation, then at $1,3,5,10$, and 15 mins after the administration of the study drug. The emergence and extubation times were noted.

Emergence time was defined as the time interval between discontinuing of anesthetic and patient following verbal commands.

Extubation time was defined as the time interval between cessation of anesthetics and tracheal extubation.

Quality of extubation was evaluated based on cough immediately after extubation, using a five-point rating scale (extubation quality score):

1. No coughing

2. Smooth extubation, minimal coughing ( 1 or 2 times)

3. Moderate coughing (3 or 4 times)

4. Severe coughing (5-10 times) and straining

5. Poor extubation, very uncomfortable (laryngospasm and coughing $>10$ times)

6. Postoperative sedation was evaluated on a six-point scale (Ramsay scale).

Ramsay scale:

1. Anxious or agitated and restless or both

2. Cooperative, oriented and tranquil

3. Drowsy but responds to commands

4. Asleep, brisk response to light glabellar tap or loud auditory stimulus

5. Asleep, sluggish response to light glabellar tap or loud auditory

6. Asleep and unarousable.

Side effects like bradycardia, hypotension, respiratory depression, laryngospasm, bronchospasm, vomiting were noted. Time of requirement of first analgesic was also noted.

Hypotension was defined as a decrease in MAP of $<30 \%$ of the baseline and was corrected with IV fluids and if required, with a small dose of mephentermine $3 \mathrm{mg} I V$. Bradycardia was defined as a HR of $<60 /$ mins and was corrected, if associated with hemodynamic instability, with atropine $0.6 \mathrm{mg}$ IV. All patients were shifted to Neurosurgical Intensive Care Unit after surgery.

\section{Statistical analysis}

Statistical analysis was done using SPSS version 15.0. Data are presented as mean (standard deviation) or number (\%). The qualitative data was compared by applying Chi-square test. The values for normal distribution blood pressure and HR were analyzed using ANOVA test. Non-parametric data were analyzed using Chi-square test. Statistical significance was accepted at $\mathrm{p}<0.05$. 


\section{RESULTS}

The patients in the two groups were comparable for age, weight and male:female ratio, ASA physical status, duration of surgery, duration of anesthesia, and the difference between the two groups was not statistically significant $(p>0.05)$ (Table 1). We observed a statistically significant difference $(p<0.05)$ in HR between the two groups from 5 mins after starting the administration of the agent till 15 mins after extubation (Table 2). The MAP between the two groups showed statistically significant difference $(\mathrm{p}<0.05)$ from 5 mins after starting the administration of the agent and continued till the time observations were made (Table 2).

We observed a significant difference in the quality of extubation between the two groups $(p<0.05)$ (Figure 1). 60\% of the patients in Group A could be extubated smoothly with minimal coughing, whereas $36 \%$ patients showed moderate coughing at the time of extubation. $52 \%$ patients in Group B showed moderate coughing at the time of extubation, whereas only $36 \%$ patients could be extubated smoothly. A significant difference in the level of post-operative sedation was observed between the two groups $(p=0.017)$.

There was no significant difference in emergence and extubation times among the two groups $(p>0.05)$. The time to first analgesic requirement was delayed after administration of dexmedetomidine $(\mathrm{p}<0.0001)$ (Table 3$) .44 \%$ of patients in Group A were drowsy, but responding to commands with a sedation score of 3, 1 patient had sedation score 6 on the Ramsay scale; whereas, in Group B, 56\% patients were cooperative, oriented, and tranquil with a sedation score of 2 on the Ramsay scale.

The incidence of bradycardia was higher in Group A compared to Group B (Table 4). Six patients in Group A developed bradycardia as compared to only one patients in the control group, but, no one required treatment. Five

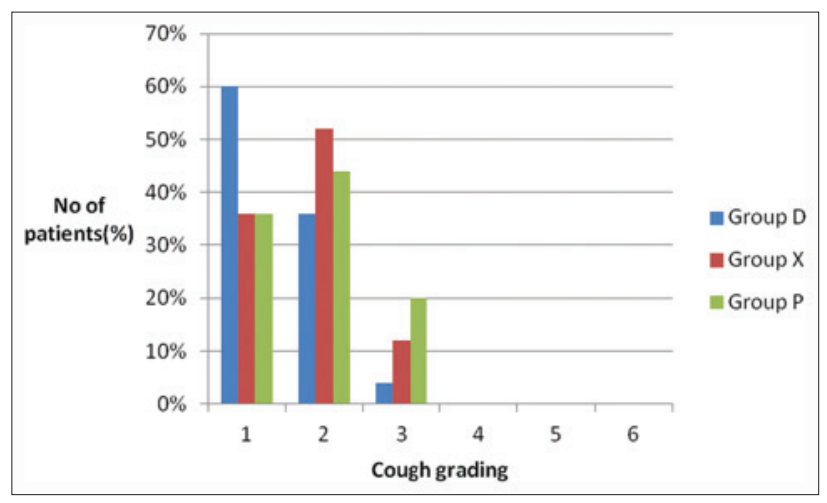

Figure 1: Quality of extubation score.

Table 1: Demographic data.

\begin{tabular}{|lccc|}
\hline Variables & Group D $(\mathbf{n = 2 5})$ & Group L (n=25) & Group P (n=25) \\
\hline Age (years) & $39.1 \pm 13.1$ & $40.5 \pm 12.24$ & $38.92 \pm 11.9$ \\
\hline Sex $(\mathrm{M} / \mathrm{F})$ & $16: 9$ & $11: 14$ & $14: 11$ \\
\hline Weight $(\mathrm{kg})$ & $55.96 \pm 11$ & $54.92 \pm 11.9$ & $52.8 \pm 11.1$ \\
\hline Duration of surgery (minutes) & $159.9 \pm 58.08$ & $162.3 \pm 55.6$ & $161.3 \pm 56$ \\
\hline Duration of anesthesia (minutes) & $148.4 \pm 56$ & $145 \pm 67$ & $141 \pm 60$ \\
\hline
\end{tabular}

Table 2: Hemodynamic data.

\begin{tabular}{|lccccccc|}
\hline \multirow{2}{*}{ Duration } & \multicolumn{3}{c}{ Heart rate } & \multicolumn{3}{c|}{ MAP } \\
\cline { 2 - 5 } & Group D & Group X & Group P & Group D & Group X & Group P \\
\hline Baseline & $78.39 \pm 11.89$ & $79.5 \pm 11.46$ & $79.67 \pm 11.6$ & $94.78 \pm 13.71$ & $96.5 \pm 14.34$ & $103.5 \pm 5.5$ \\
\hline Immediate after extubation & $76.26 \pm 14.88^{* *}$ & $87 \pm 10.57$ & $88.83 \pm 12.7$ & $97.04 \pm 11.53$ & $114 \pm 17.25$ & $103 \pm 9.6 * *$ \\
\hline 1 min & $74.04 \pm 13.94 * *$ & $87.3 \pm 10.56$ & $90 \pm 10.2$ & $92.52 \pm 10.62$ & $103.4 \pm 10.19$ & $101.67 \pm 10.5 * *$ \\
\hline 3 mins & $72.48 \pm 12.98^{* *}$ & $86.1 \pm 10.35$ & $82.5 \pm 12.8$ & $91.17 \pm 11.32$ & $108.2 \pm 10.57$ & $101.17 \pm 9.4 * *$ \\
\hline 5 mins & $72.26 \pm 11.42^{* *}$ & $81.1 \pm 8.8$ & $75.67 \pm 14.07$ & $89.48 \pm 9.69$ & $104.4 \pm 10.03$ & $100.67 \pm 11.2 * *$ \\
\hline 10 mins & $72.43 \pm 11.19 * *$ & $77 \pm 9.79$ & $75.67 \pm 11.5$ & $86.91 \pm 11.27$ & $99.3 \pm 7.22$ & $99.5 \pm 10.6 *$ \\
\hline 15 mins & $72.22 \pm 10.87 * *$ & $74.2 \pm 8.9$ & $78 \pm 13.9$ & $85.39 \pm 10.0$ & $95.2 \pm 7.39$ & $97.67 \pm 11.4 *$ \\
\hline
\end{tabular}

$\mathrm{p}>0.05$ non-significant, ${ }^{*} \mathrm{p}<0.05$ significant, ${ }^{* *} \mathrm{p}<0.001$ highly significant, MAP: Mean arterial pressure

Table 3: Intra operative and post-operative data.

\begin{tabular}{|lcccc|}
\hline Duration & Group D & Group L & Group P & p value \\
\hline Extubation time (minutes) & $10.1 \pm 1.4$ & $9.3 \pm 2.1$ & $7.9 \pm 1.2$ & 0.1196 \\
\hline Emergence time (minutes) & $8.7 \pm 2.6$ & $7.3 \pm 7.2$ & $6.1 \pm 2.4$ & 0.3651 \\
\hline Time of first analgesic (minutes) & $24 \pm 6.6$ & $12.1 \pm 5.1$ & $8.9 \pm 3.1$ & 0.0001 \\
\hline
\end{tabular}


patients in Group A developed hypertension, seven of the patients in Group B developed hypertension. One patient in Group A and two in Group B had vomiting after extubation. None of the patients in either group had any of the other side effects like vomiting, respiratory depression, laryngospasm, bronchospasm, undue sedation (Table 4).

\section{DISCUSSION}

Extubation can be associated with several complications like coughing and respiratory complications (laryngospasm, airway obstruction, desaturation) and hemodynamic changes. $^{3}$

Numerous strategies have been used to prevent hemodynamic responses caused by emergence from anesthesia including extubation under deep anesthesia, administration of local anesthetics, vasodilators and short-acting opioids. ${ }^{4}$ Administering vasodilators such as sodium nitroprusside, nitroglycerin, and hydralazine could be associated with complications like reflexive tachycardia and increase in the plasma renin activity. ${ }^{5}$

In our during study we used dexmedetomidine during extubation as it is a highly selective $\alpha-2$ agonist that has been shown to have sedative, analgesic, and anesthetic sparing effect. It causes a dose-dependent decreased arterial blood pressure and HR associated with a decrease in plasma catecholamines. ${ }^{6}$ There was no clinically apparent respiratory depression after cessation of assisted ventilation. Dexmedetomidine produced rapid and stable sedation in postsurgical ventilated patients while maintaining a high degree of patient rousability and anxiety reduction. ${ }^{7}$

In the present study, dexmedetomidine $0.5 \mu \mathrm{g} / \mathrm{kg}$ IV given before tracheal extubation was associated with significantly less coughing and better quality of extubation than lignocaine and placebo.

We found that most patients in dexmedetomidine group were sedated, but responding to verbal commands (Ramsay sedation scale 3) after extubation when compared to Group L and Group P where most patients belonged to Ramsay sedation scale 2 .

Table 4: Adverse effect.

\begin{tabular}{|lccc|} 
& $\begin{array}{c}\text { Group D } \\
(\%)\end{array}$ & $\begin{array}{c}\text { Group L } \\
(\%)\end{array}$ & $\begin{array}{c}\text { Group P } \\
(\%)\end{array}$ \\
\hline Bradycardia & $6(24)$ & $1(4)$ & - \\
\hline Hypotension & - & - & - \\
\hline Hypertension & $5(20)$ & $7(28)$ & $4(16)$ \\
\hline Respiratory depression & - & - & - \\
\hline Bronchospasm & - & - & - \\
\hline Laryngospasm & - & - & - \\
\hline Vomiting & - & - & - \\
\hline
\end{tabular}

Aksu et al. ${ }^{3}$ found dexmedetomidine $0.5 \mu \mathrm{g} / \mathrm{kg}$, given 5 mins before extubation has been found to be more effective than fentanyl $1 \mu \mathrm{g} / \mathrm{kg}$ in attenuating airway reflex responses to tracheal extubation and maintaining hemodynamic stability without prolonging recovery. In our study, the incidence of bradycardia and hypotension was higher in Group D than Group L and Group P. In our study, none of the patients in either group developed respiratory depression, laryngospasm, bronchospasm, undue sedation or desaturation. Similar findings have been made by Bindu et al. ${ }^{8}$

Guler et al. ${ }^{9}$ Found median coughing scores were 1 in the dexmedetomidine group and 2 in the placebo $(p<0.05)$, but there were no differences between the groups in the incidence of breath holding or desaturation. HR, SAP, and DAP increased at extubation in both groups $(\mathrm{p}<0.05)$, but the increase was less significant with dexmedetomidine which is comparable with our study.

In $20 \%$ of cases, we observed immediate hypertension following dexmedetomidine. ${ }^{2}$ The effect of $\alpha-2$ agonists on hemodynamics is biphasic: an immediate increase in systemic arterial pressure (mediated by stimulation of peripheral $\alpha-2 B$ receptor) followed by a longer-lasting reduction in pressure caused by stimulation of $\alpha-2$ adrenoceptor in central nervous system. ${ }^{10,11}$ Sharma et al. ${ }^{12}$ observed MAPs increased in the first 2 mins after the dexmedetomidine administration and returned to normal after 3 mins. We also found similar observation. $\alpha-2$ agonists have been recognized as having analgesic effects. In our study, we also noted the time for the first analgesic after extubation which was significantly delayed $(\mathrm{p}<0.0001)$ in Group $\mathrm{D}$, our finding matches with Sharma et al. ${ }^{12}$

\section{CONCLUSION}

Single bolus dose of IV dexmedetomidine $\mathrm{HCl}$ $0.5 \mathrm{mg} / \mathrm{kg}$ given before tracheal extubation effectively attenuate hemodynamic response to extubation as compared to $1.5 \mathrm{mg} / \mathrm{kg}$ lignocaine $\mathrm{HCl}$.

\section{Funding: No funding sources}

Conflict of interest: None declared

Ethical approval: The study was approved by the Institutional Ethics Committee

\section{REFERENCES}

1. Moein Vaziri MT, Jouybar R, Moein Vaziri N, Moein Vaziri N, Panah A. Attenuation of cardiovascular responses and upper airway events to tracheal extubation by low dose propofol. Iran Red Crescent Med J. 2013;15(4):298-301.

2. Afonso J, Reis F. Dexmedetomidine: current role in anesthesia and intensive care. Rev Bras Anestesiol. 2012;62(1):118-33.

3. Aksu R, Akin A, Biçer C, Esmaoğlu A, Tosun Z, Boyaci A. Comparison of the effects of dexmedetomidine versus fentanyl on airway reflexes and hemodynamic responses to tracheal extubation during rhinoplasty: a double-blind, 
randomized, controlled study. Curr Ther Res Clin Exp. 2009;70(3):209-20.

4. Hohlrieder M, Tiefenthaler W, Klaus H, Gabl M, Kavakebi P, Keller C, et al. Effect of total intravenous anaesthesia and balanced anaesthesia on the frequency of coughing during emergence from the anaesthesia. $\mathrm{Br} \mathrm{J}$ Anaesth. 2007;99(4):587-91.

5. Unal Y, Ozsoylar O, Sariguney D, Arsalan M, Yardim RS. The efficacy of esmolol to blunt the hemodynamic response to endotracheal extubation in lumbar disc surgery. Res. J Med Sci. 2008;2:99-104.

6. Kallio A, Scheinin M, Koulu M, Ponkilainen R, Ruskoaho H, Viinamäki O, et al. Effects of dexmedetomidine, a selective alpha 2-adrenoceptor agonist, on hemodynamic control mechanisms. Clin Pharmacol Ther. 1989;46:33-42.

7. Bhana N, Goa KL, McClellan KJ. Dexmedetomidine. Drugs. 2000;59(2):263-8.

8. Bindu B, Pasupuleti S, Gowd UP, Gorre V, Murthy RR, Laxmi MB. A double blind, randomized, controlled trial to study the effect of dexmedetomidine on hemodynamic and recovery responses during tracheal extubation. J Anaesthesiol Clin Pharmacol. 2013;29:162-7.

9. Guler G, Akin A, Tosun Z, Eskitascoglu E, Mizrak A, Boyaci A. Single-dose dexmedetomidine attenuates airway and circulatory reflexes during extubation. Acta Anaesthesiol Scand. 2005;49(8):1088-91.

10. Bloor BC, Ward DS, Belleville JP, Maze M. Effects of intravenous dexmedetomidine in humans. II. Hemodynamic changes. Anesthesiology. 1992;77(6):1134-42.

11. Tanskanen PE, Kyttä JV, Randell TT, Aantaa RE. Dexmedetomidine as an anaesthetic adjuvant in patients undergoing intracranial tumour surgery: a double-blind, randomized and placebo-controlled study. $\mathrm{Br} \mathrm{J}$ Anaesth. 2006;97(5):658-65.

12. Sharma VB, Prabhakar H, Rath GB, Bithal PK. Comparison of dexmedetomidine and lignocaine on attenuation of airway and pressor responses during tracheal extubation. $\mathrm{J}$ Neuroanaesth Crit Care. 2014;1:50-5.

doi: $10.5455 / 2319-2003 . i j b c p 20150442$

Cite this article as: Gosai ND, Jansari AH, Solanki RN, Patel DP, Prajapati DN, Patel BM. A comparative study of the effect of dexmedetomidine and lignocaine on hemodynamic responses and recovery following tracheal extubation in patients undergoing intracranial surgery. Int $\mathrm{J}$ Basic Clin Pharmacol 2015;4:371-5. 